\title{
COBERTURA FLORESTAL NO TRECHO URBANO DA ÁREA DE PRESERVAÇÃO PERMANENTE DO RIO ITAPEMIRIM, MUNICÍPIO DE CACHOEIRO DE ITAPEMIRIM-ES, BRASIL
}

Caio Henrique Ungarato Fiorese ${ }^{1}$, Vinícius Rocha Leite ${ }^{2}$, Tatiana da Silva Lopes ${ }^{3}$

${ }^{1}$ Graduando em Engenharia Ambiental pelo Centro Universitário São Camilo, Cachoeiro de Itapemirim, Espírito Santo, Brasil. (caiofiorese@hotmail.com). ${ }^{2}$ Professor Assistente do curso de Engenharia Ambiental do Centro Universitário São Camilo, Cachoeiro de Itapemirim, Espírito Santo, Brasil.

${ }^{3}$ Professora do colegiado de Ciências Biológicas do Centro Universitário São Camilo, Cachoeiro de Itapemirim, Espírito Santo, Brasil.

Recebido em: 06/04/2019 - Aprovado em: 10/06/2019 - Publicado em: 30/06/2019 DOI: 10.18677/EnciBio_2019A64

\begin{abstract}
A ocupação desordenada de áreas adjacentes aos cursos hídricos têm acarretado diversos problemas ambientais nas cidades brasileiras, como a impermeabilização do solo e danos à biodiversidade associada. $O$ objetivo deste trabalho foi estudar a Área de Preservação Permanente (APP) do rio Itapemirim, em seu trecho na área urbana de Cachoeiro de Itapemirim (ES), e propor sugestões para melhorias na preservação da paisagem. Fotografias aéreas de alta resolução do ano de 2012 e a feição contendo a zona urbana do município foram adquiridas junto ao banco de dados do GEOBASES e IJSN. No ArcGIS®, os arquivos foram manipulados por meio de um Sistema de Informações Geográficas seguindo com um mapeamento e quantificação dos remanescentes da cobertura florestal em toda a APP e por bairros abrangidos pelo manancial estudado. Em 2012, a vegetação ciliar correspondeu a 63,6 hectares que representam 28,97\% da APP total. Nos 19 bairros abrangidos pela APP do rio, apenas um apresentou percentual de cobertura florestal acima de $40 \%$, ao passo que vários bairros tiveram percentuais inferiores a $20 \%$. A vegetação foi encontrada sob a forma de indivíduos arbóreos isolados e pequenos fragmentos, consequência da forte ação antrópica e da urbanização intensa, o que pode agravar enchentes e a deteriorar da qualidade ambiental dos recursos hídricos e da cidade como um todo. Medidas como a preservação dos resquícios de vegetação, ampliação da cobertura florestal e trabalhos de educação ambiental continuadamente são relevantes para amenizar os intensos efeitos da ação humana sobre a APP no percurso analisado.
\end{abstract}

RESUMO

PALAVRAS-CHAVE: Ação Antrópica; Conservação dos Recursos Hídricos; Planejamento Urbano. 


\title{
STUDY OF FOREST COVERAGE IN THE URBAN AREA OF THE PERMANENT PRESERVATIVE AREA OF THE ITAPEMIRIM RIVER, MUNICIPALITY OF CACHOEIRO DE ITAPEMIRIM-ES, BRAZIL
}

\begin{abstract}
The disordered occupation of areas adjacent to the watercourses has caused several environmental problems in Brazilian cities, such as waterproofing of soils and damage to the associated biodiversity. The objective of this work was to study the Permanent Preservation Area (PPA) of the Itapemirim River, in its stretch in the urban area ofCachoeiro de Itapemirim (ES), and to propose suggestions for improvements in landscape preservation. High resolution aerial photographs of the year 2012 and the feature containing the urban area of the municipality were acquired in conjunction with the GEOBASES and IJSN database. In ArcGIS®, the files were manipulated through a Geographic Information System followed by a mapping and quantification of forest cover remnants throughout the PPA and districts covered by the stock under study. In 2012, the riparian vegetation corresponded to 63.6 hectares, representing $28.97 \%$ of the total PPA. In the 19 districts covered by the PPA of the river, only one had a percentage of forest cover over $40 \%$, while several districts had percentages lower than $20 \%$. The vegetation was found in the form of isolated arboreal individuals and small fragments, a consequence of the strong anthropic action and intense urbanization, which can aggravate the floods and deteriorate the environmental quality of the water resources and of the city as a whole. Measures such as the preservation of remnants of vegetation, the expansion of forest cover and environmental education work are continuously relevant to alleviate the intense effects of human action on APP in the analyzed course.
\end{abstract}

KEYWORDS: Anthropogenic Action; Conservation of Water Resources; Urban Planning.

\section{INTRODUÇÃO}

A degradação de recursos naturais, como é o caso da cobertura vegetal, vem sendo motivo de discussões e grande preocupação em âmbito político, social e econômico, sendo que a redução desses recursos afeta diretamente a quantidade e qualidade da água, bem como gera graves problemas socioeconômicos e ambientais (BAPTISTA, 2009; PEREIRA et al., 2016).

No Brasil, a necessidade de estabelecer normas gerais para uso e proteção das faixas ciliares levou à inclusão dessas áreas no âmbito do Código Florestal de 1965 que foram mantidas na sua atualização pela promulgação da lei $n^{\circ}$ 12.651/2012, sendo denominadas de Áreas de Preservação Permanente (APPs). As APPs tiveram suas primeiras noções legais no Código de 1934, em que foram estabelecidas as florestas protetoras e seus remanescentes e, posteriormente, elas foram definidas como Área de Preservação Permanente (APP) (ROSA, 2011).

O novo Código Florestal Brasileiro (BRASIL, 2012) conceitua as áreas de preservação permanente como sendo áreas protegidas, cobertas ou não por vegetação nativa, com as seguintes funções ambientais: preservar os recursos hídricos, a paisagem, a estabilidade geológica e a biodiversidade; facilitar a troca genética entre as espécies da fauna e flora, proteger o solo e assegurar o bem-estar da população humana. 
As agressões causadas pela ação antrópica nas APPs causam aos rios uma perda significativa de sua mata ciliar, além da biodiversidade local. A lei, prevista para proteger essa vegetação, entretanto, não consegue conter 0 avanço e 0 crescimento desenfreado das cidades (FERREIRA; MENEGUELLI, 2017). Com isso, nos últimos anos, a redução das áreas naturais tem levado à fragmentação florestal, fenômeno em que a vegetação natural é interrompida pela existência de barreiras antrópicas capazes de comprometer as funções ecológicas básicas dos ecossistemas (PÉRICO; CEMIN, 2006). As intervenções sobre o meio ambiente urbano ocorrem de forma cada vez mais intensa, tanto na abertura de espaço para a construção de novos condomínios quanto na abertura de novas vias urbanas e outros efeitos danosos resultantes da urbanização (DAMASCENO et al., 2013).

As matas ciliares exercem importantes funções ambientais como, por exemplo, funcionam como corredores de fauna entre fragmentos florestais fornecem abrigo para várias espécies animais (mamíferos, pássaros, anfíbios, etc) e concentram diversas espécies da flora nativa (CASTRO et al., 2017). Nas cidades, essa vegetação é capaz de reduzir a velocidade das águas precipitadas via escoamento superficial e a infiltração por parte das raízes minimiza o assoreamento do curso hídrico, melhorando também parâmetros importantes de qualidade da água, como a turbidez (ALMEIDA et al., 2011). Além disso, a presença da vegetação aliada ao regimento correto dos instrumentos legais de proteção nas zonas urbanas pode contribuir significativamente no aperfeiçoamento do planejamento e governança ambiental urbana (KUDO et al., 2016).

$\mathrm{Na}$ área urbana do município de Cachoeiro de Itapemirim (ES), a importância da preservação da vegetação ciliar em torno do seu rio principal, o Rio Itapemirim, e dos córregos urbanos associados está ligada também a redução da poluição aquática e, consequentemente, na melhoria da qualidade de vida local. Contudo, assim como em várias cidades, Cachoeiro de Itapemirim teve seu processo de urbanização de forma desordenada, sendo visível a presença de várias ocupações irregulares às margens do Rio Itapemirim em detrimento à vegetação que deveria predominar nesses locais (LOUGON et al., 2009).

Nesse sentido, os Sistemas de Informação Geográfica (SIGs) e o Sensoriamento Remoto são importantes recursos da área das geotecnologias capazes de fornecer subsídios para planejar a minimização de impactos ambientais (BARROS et al., 2015). As tecnologias de geoprocessamento são essenciais no monitoramento dos recursos naturais, considerando que as informações geradas a partir de sensores de satélite são fundamentais para o estudo do ambiente geográfico, identificando a degradação das áreas e estimando índices de vegetação (LIMA et al., 2018). Assim, a informação geoespacial busca na cartografia temática a exposição de dados geográficos de forma clara, oferecendo suporte às definições estratégicas e importantes no ordenamento equilibrado do território (ORIGE et al., 2015).

O objetivo deste trabalho foi realizar um estudo da cobertura vegetal remanescente na Área de Preservação Permanente do rio Itapemirim em seu curso na zona urbana de Cachoeiro de Itapemirim-ES, bem como propor sugestões de planejamento ambiental. 


\section{MATERIAL E MÉTODOS}

A área estudada fica localizada no município de Cachoeiro de Itapemirim, na macrorregião Sul do Estado do Espírito Santo. O rio Itapemirim é o principal recurso hídrico do município de Cachoeiro de Itapemirim, sendo vital para o abastecimento na cidade e de municípios na região. A bacia hidrográfica do rio abastece 17 municípios, atendendo cerca de 410 mil habitantes, o correspondente a $25 \%$ da população do estado do Espírito Santo (ALVES et al., 2003).

A cidade de Cachoeiro de Itapemirim está situada nas coordenadas geográficas ( $20^{\circ} 50^{\prime} 58^{\prime \prime} \mathrm{S}$ e $41^{\circ} 6^{\prime}$ '48" O), sendo considerada uma cidade de médio porte para o estado do Espírito Santo (PIROVANI et al., 2012). Segundo dados do Instituto Brasileiro de Geografia e Estatística (IBGE), referentes a informações obtidas para o censo de 2010, o município possuía 189.889 habitantes, sendo 173.589 residentes na zona urbana (IBGE, 2010). Na Figura 1 é possível observar a paisagem circundante e o rio Itapemirim.

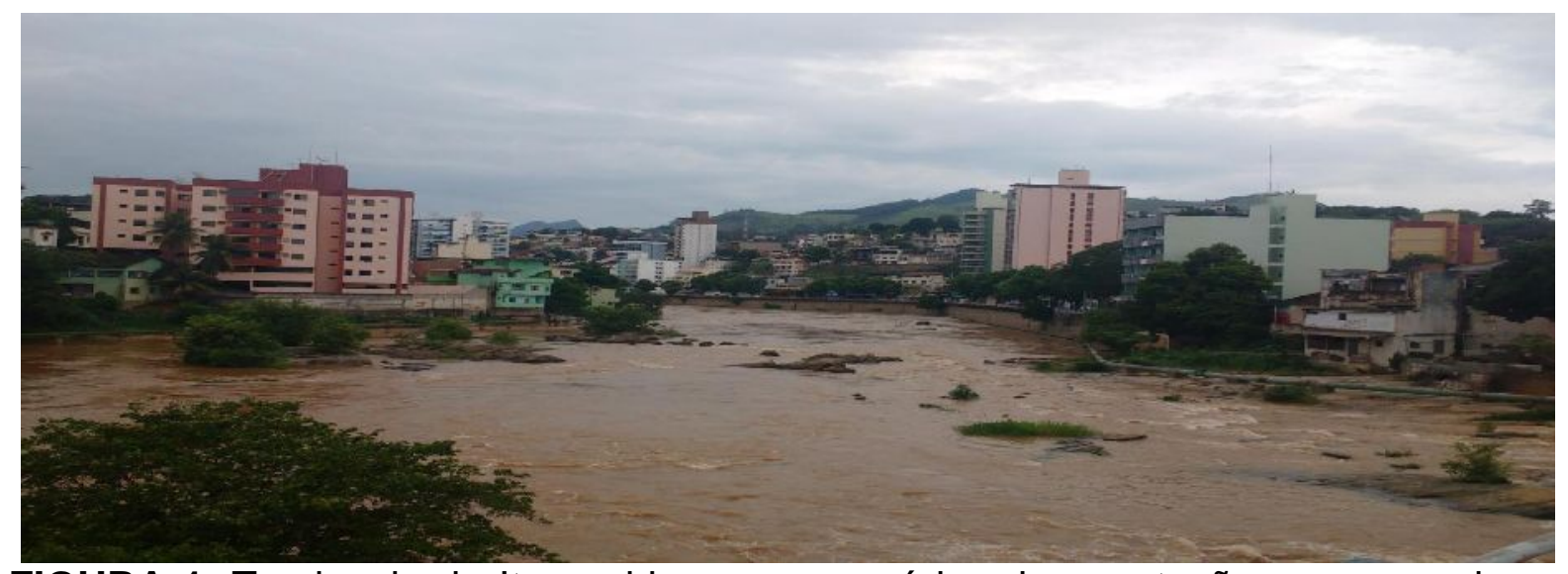

FIGURA 1. Trecho do rio Itapemirim com resquícios de vegetação na zona urbana de Cachoeiro de Itapemirim-ES. Fonte: Os Autores (2019).

Como banco de dados cartográficos foram utilizados o sítio eletrônico do Sistema Integrado de Bases Geoespaciais do Estado do Espírito Santo (GEOBASES) e o Instituto Jones dos Santos Neves (IJSN), além do programa ArcGIS $\AA 10.2$ para a execução dos procedimentos computacionais. No GEOBASES, imagens aéreas referentes ao mapeamento realizado no ano de 2012 foram coletadas, com resolução espacial de 1 metro. Junto ao site do IJSN, as feições dos bairros das zonas urbanas do estado do Espírito Santo foram adquiridas, fazendo recorte da área urbana do município de Cachoeiro de Itapemirim.

Inicialmente, através da fotointerpretação das feições em escala 1:900, a linha de fluxo do rio Itapemirim foi traçada no trecho que passa pela área urbanizada da cidade estudada. Para delimitar a Área de Preservação Permanente (APP), a largura o Rio Itapemirim foi medida com base no recurso measure para, em seguida, verificar a adoção do valor da largura de APP a ser considerada, de acordo com o Código Florestal Brasileiro (BRASIL, 2012). A delimitação da APP no Sistema de Informações Geográficas foi realizada através da ferramenta buffer, definindo 100 metros conforme a legislação aplicável, devido ao fato da largura do rio estar entre 50 a 200 metros.

Em seguida, as imagens aéreas referentes a cada mapeamento foram fotointerpretadas para permitir a identificação da cobertura florestal por criação de 
novas feições, por meio de um arquivo novo em formato shapefile representando a vegetação da APP de cada mapeamento.

Após a identificação inicial da cobertura vegetal, por meio da criação e edição de um campo denominado "área" na tabela de atributos de cada arquivo elaborado, foi estimada a área, em metros quadrados, e o percentual de vegetação arbórea existente no ano de 2012, período que possuía fotografia aérea disponibilizada pelo estado. Um mapa temático foi feito e permitiu a observação e a interpretação da distribuição espacial dos resquícios de vegetação florestal da APP analisada.

Com intuito de analisar o quantitativo de mata ciliar do rio Itapemirim na APP, em metros quadrados $\left(\mathrm{m}^{2}\right)$ e porcentagem (\%), de cada bairro da zona urbana de Cachoeiro de Itapemirim, um arquivo shapefile foi adquirido no sítio eletrônico do IJSN, referente a limites de bairros. A identificação dos bairros abrangidos pela APP do rio Itapemirim foi feita através do recurso identify, nas informações contidas na tabela de atributos. Para cada bairro, um novo arquivo vetorial foi criado para, em seguida, usando o recurso clip, delimitar a vegetação florestal existente na APP do rio Itapemirim no território de cada bairro. As análises observadas quanto à distribuição e quantificação da cobertura vegetal foram descritas em consonância com a literatura considerada, visando identificar parâmetros que pudessem ser associados a atual condição quantitativa da APP com cobertura florestal encontrada (SILVA NETO et al., 2016; SANTOS, 2018).

\section{RESULTADOS E DISCUSSÃO}

Para o percurso do rio Itapemirim analisado, sua Área de Preservação Permanente (APP) possui largura de 100 metros e corresponde a 219,7 hectares de área, o equivalente a $1,9 \%$ da área total urbana da cidade de Cachoeiro de Itapemirim. No ano de 2012, a vegetação ciliar correspondeu a 63,6 hectares, em torno de $28,9 \%$ da APP total. Percentual, porém, inferior ao visto em outros trabalhos, como o de Fiorese (2018), que obteve valores superiores a $40 \%$ para a APP do rio Castelo, na zona urbana de Conceição do Castelo-ES, e o de Silva Neto et al. (2016), que encontraram 49,3\% de mata ciliar na APP do Córrego Dois Irmãos na zona urbana do município de Gurupi/TO. Apesar de esses autores terem encontrados índices superiores de APP, quando comparado ao do presente estudo, eles também relatam impactos semelhantes aos encontrados no rio Itapemirim como é o caso da construção de edificações nas APPs que ocorre até os dias atuais.

Um aspecto que chama a atenção, referente a essa continuidade dos impactos sobre as APPs até os dias atuais é o fato de que embora elas possuam o amparo na legislação para sua proteção, esse status ainda é pouco considerado e ainda é contínua a interferência antrópica, como a supressão continuada da vegetação provocada pela ação antrópica. Além disso, a importância das APPs é desconhecida em sua totalidade, pois a sociedade ainda não compreende bem a capacidade que elas possuem de geração de serviços ecossistêmicos, como a preservação da biodiversidade e a redução dos riscos causados por eventos extremos advindos das mudanças climáticas (SILVA; LOPES, 2016).

A legislação ambiental brasileira é uma das mais complexas e rigorosas do mundo, todavia, a fiscalização e penalização inadequadas são evidentes. As APPs, mesmo com o amparo da lei, ficaram vulneráveis à devastação de sua vegetação (AMARAL et al., 2015). Isso fez com que, ao longo do tempo, as ações de preservação se tornassem cada vez mais difíceis de serem executadas. A aplicação 
de medidas mitigadoras nas APPs da zona urbana é diferente da realizada em âmbito rural (GUIMARÃES; BRAGA, 2017). Na APP do percurso do rio analisado, a aplicação de ações de preservação dos poucos remanescentes de mata ciliar é de extrema importância, pois a ampliação da cobertura vegetal nessa área é praticamente impossível tendo em vista a intensa urbanização da cidade e os custos elevados com a recuperação ambiental e a desocupação de moradores irregulares (SILVA NETO et al., 2016).

A Tabela 1 e a Figura 3 apresentam, respectivamente, os valores de área referente à vegetação florestal e o percentual de cobertura vegetal em relação ao trecho total de APP que passa por cada bairro do município de Cachoeiro de Itapemirim, bem como a representação em mapa temático dos percentuais de vegetação.

TABELA 1. Vegetação ciliar, em metros quadrados $\left(m^{2}\right)$ e porcentagem, referente à APP do segmento do rio Itapemirim no ano de 2012.

\begin{tabular}{ccc}
\hline Bairros & Área $\left.\mathbf{( m}^{\mathbf{2}}\right)$ & Percentual \\
\hline Rubem Braga & $38.793,88$ & $32,80 \%$ \\
\hline Novo Parque & $5.000,64$ & $7,37 \%$ \\
\hline Aquidabam & $18.661,92$ & $12,80 \%$ \\
\hline Ibitiquara & $7.710,13$ & $15,69 \%$ \\
\hline Independência & $19.545,22$ & $19,78 \%$ \\
\hline Coronel Borges & $44.876,85$ & $32,94 \%$ \\
\hline Alvaro Tavares & $74.639,50$ & $41,58 \%$ \\
\hline Nossa Senhora da Glória & $8.042,00$ & $27,70 \%$ \\
\hline Arariguaba & $81.696,21$ & $37,18 \%$ \\
\hline Baiminas & $19.577,71$ & $20,82 \%$ \\
\hline Amaral & 744,06 & $11,50 \%$ \\
\hline Alto Amarelo & $3.522,18$ & $23,91 \%$ \\
\hline Centro & $20.177,97$ & $12,13 \%$ \\
\hline Guandu & $7.530,17$ & $9,68 \%$ \\
\hline Maria Ortiz & $3.111,92$ & $16,12 \%$ \\
\hline Vila Rica & $1.056,34$ & $15,87 \%$ \\
\hline Ilha da Luz & $34.399,86$ & $19,00 \%$ \\
\hline Teixeira Leite & $32.279,60$ & $25,07 \%$ \\
\hline Valão & $18.589,08$ & $23,82 \%$
\end{tabular}




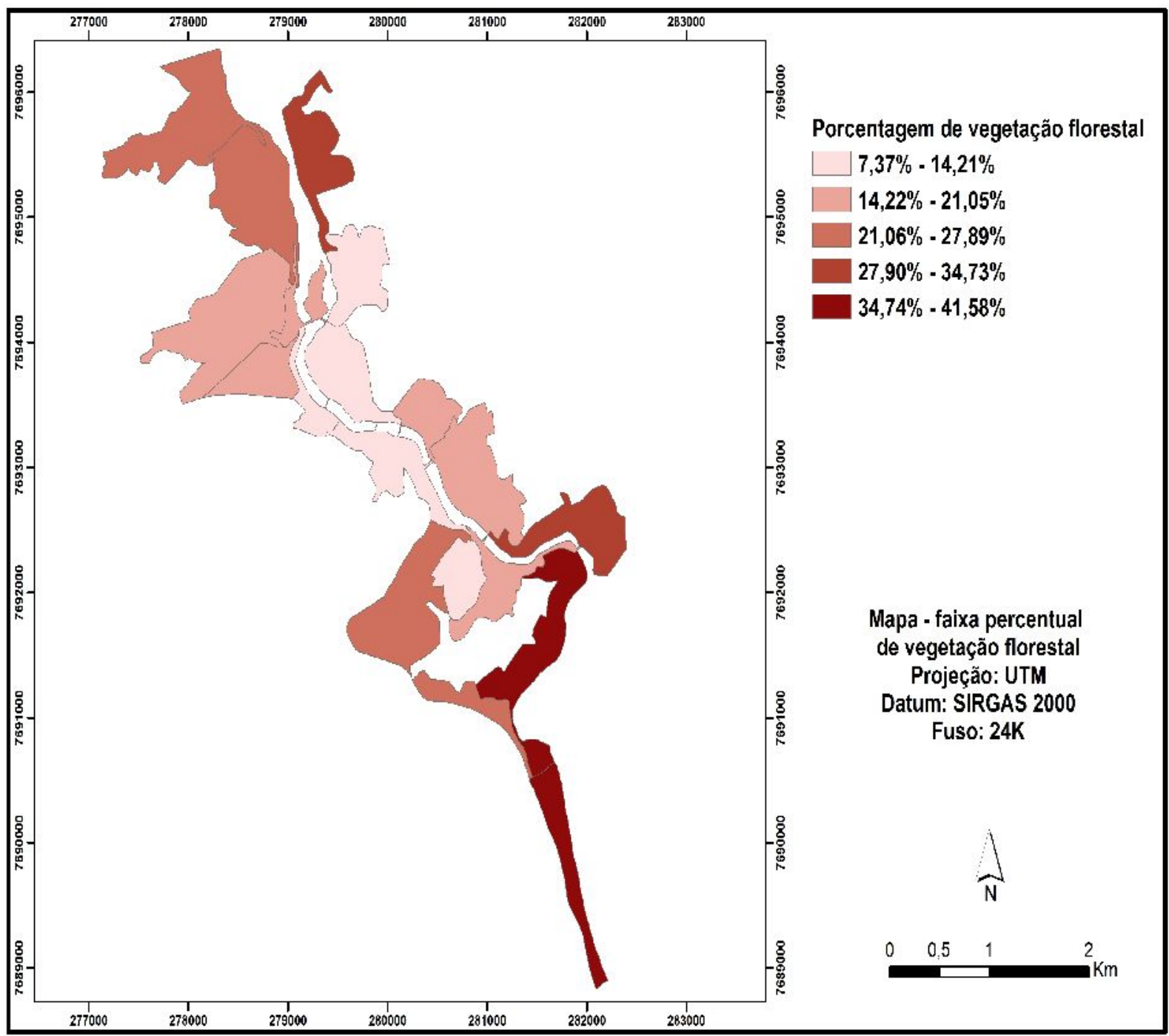

FIGURA 3. Percentual de mata ciliar em relação à área total de APP de cada bairro abrangido pelo Rio Itapemirim. Fonte: Os Autores (2019).

No caso do município de Cachoeiro de Itapemirim-ES, a forte ocupação desordenada, tanto em encostas quanto às margens do rio Itapemirim, juntamente com a baixa eficácia da atuação do poder público municipal, provocou a redução drástica da vegetação nativa nas APPs. As construções antrópicas passaram a, inclusive, invadir a calha maior do rio, o que pode acarretar em aumento dos picos de enchentes e deterioração da qualidade hídrica, em decorrência do aumento da impermeabilidade do solo. Vestena e Thomaz (2006) afirmam que a preservação da mata ciliar contribui na redução da velocidade de escoamento das águas superficiais e dificulta o despejo de lixo, que constitui outro agravante presente na APP investigada.

Os percentuais tiveram variação de até aproximadamente $34 \%$, sendo que os bairros Álvaro Tavares e Novo Parque apresentaram, respectivamente, o maior e o menor percentual. Dos 19 bairros abrangidos pela APP do rio Itapemirim, 10 apresentaram percentuais inferiores a $20 \%$, o que constitui um motivo de preocupação quanto à proteção do referido curso hídrico nessas localidades e a 
qualidade ambiental e de vida local, além da necessidade de ações de preservação e conservação da mata ciliar com maior prioridade nos referidos bairros.

Os resultados obtidos com relação à análise dos bairros ilustram inicialmente os maiores valores de cobertura florestal para o caso do bairro Álvaro Tavares, devido ao fato de este constituir um bairro localizado ao sul da faixa urbanizada da cidade, em região periférica, com baixa ocupação imobiliária e ocorrência de pastagens com cobertura florestal em trechos da área ciliar. Já o bairro Novo Parque com pouca cobertura florestal estimada é provável decorrência do baixo nível de arborização urbana e pela existência de diversas habitações em que houve um processo de invasão ao longo do tempo, em terrenos com declividade acentuada, que é uma característica geomorfológica do município.

Moreira e Souza (2018) afirmam que a mata ciliar, também denominada mata de galeria, exerce atuação fundamental na manutenção do equilíbrio geoecológico dos sistemas de drenagem, sendo que o desmatamento desses espaços pode agravar processos erosivos acelerados e comprometer a dinâmica do fluxo de água para a superfície. No caso do presente estudo essa é uma problemática associada aos bairros em que o processo de construção foi feito sem planejamento e sobre terrenos de baixa estabilidade. De forma geral, a situação da APP estudada é preocupante, uma vez que a faixa de vegetação ciliar adjacente a este curso hídrico, em alguns pontos, é praticamente inexistente, com a predominância de residências, vias públicas e demais construções humanas.

Apenas para 4 bairros foram estimados percentuais de vegetação florestal superiores a $30 \%$ e, conforme a Figura 3, somente 2 bairros apresentaram valores superiores a $34,74 \%$. Os bairros que apresentaram percentuais inferiores a $14,21 \%$ estão localizados próximos ao centro da cidade evidenciando maior devastação da mata ciliar nestes locais.

A Figura 4 mostra a distribuição da vegetação florestal na APP do Rio Itapemirim na zona urbana do município. Nota-se que os remanescentes de vegetação florestal observados encontram-se distribuídos de forma isolada e menos contínua ao longo da APP do rio Itapemirim, dispostos, em maior parte, na arborização de calçadas e quintais de residências. Esse é um padrão de quantidade de habitats reduzida que também está relacionado à formação de barreiras para a perpetuação da fauna local e na manutenção de um ambiente com maior sustentabilidade ambiental. 


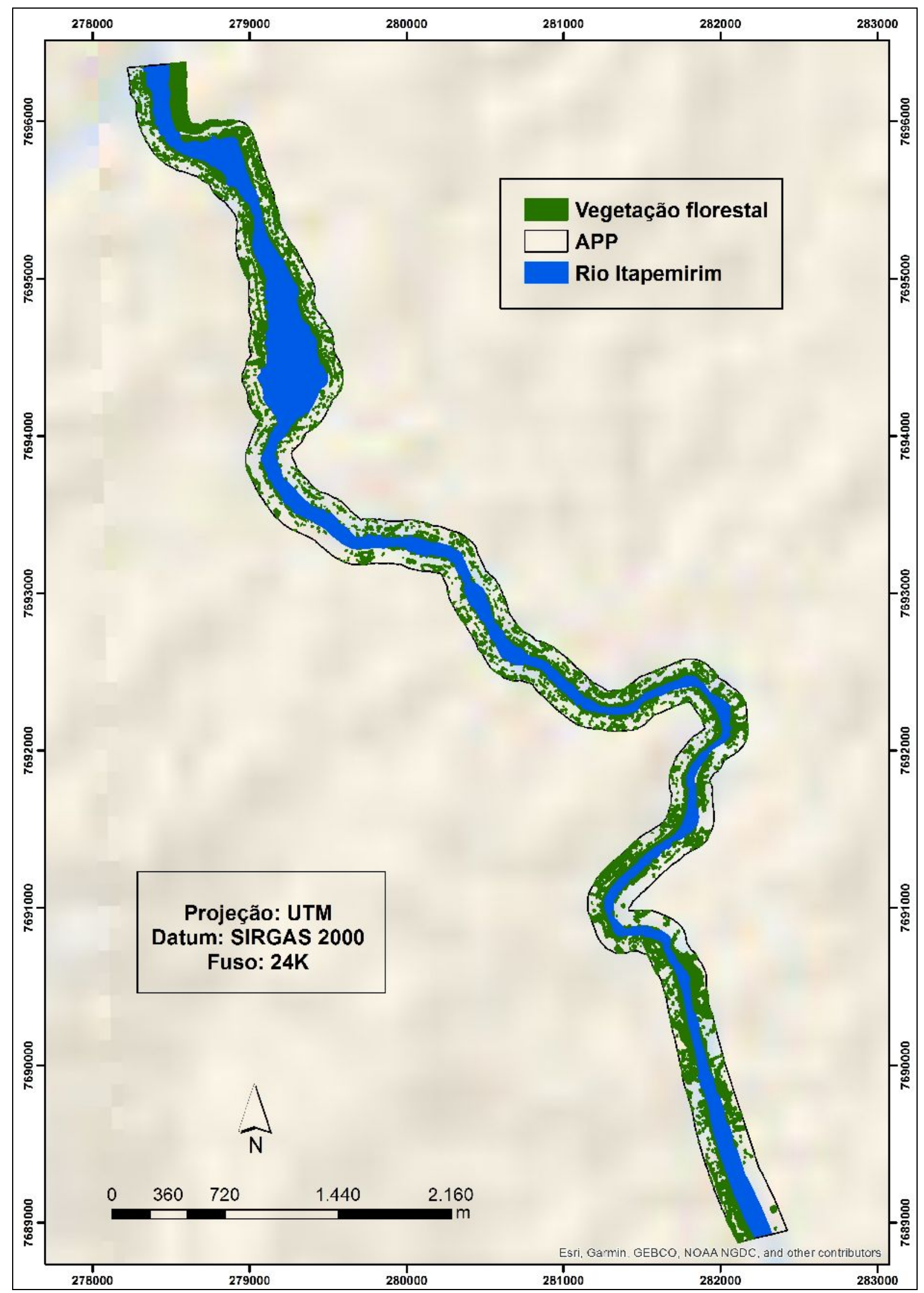

FIGURA 4. Distribuição geoespacial da cobertura vegetal da APP do trecho urbano analisado. Fonte: Os Autores (2019). 
A importância do mapeamento das APPs se deve ao fato de constituir um instrumento importante que facilita a preservação ao subsidiar ações de fiscalização e licenciamento ambiental (OLIVEIRA; FRANCISCO, 2018). No caso do município de Cachoeiro de Itapemirim, o mapeamento da APP do rio Itapemirim permitiu observar que, historicamente, houve grande interferência antrópica e a vegetação, outrora espalhada uniformemente pela área, passou a se concentrar árvores e fragmentos isolados e, em vários pontos, estando ausentes na calha do rio.

Em Cachoeiro de Itapemirim, essa interferência humana se deve ao processo de urbanização da cidade, que culminou na ocupação desordenada da APP e no isolamento da vegetação. Problemas semelhantes aos de muitas cidades brasileiras como, por exemplo, no município de Humaitá-AM (LIMA et al., 2018). Os mesmos autores, constataram na APP do Rio Belém a ocorrência de diversos impactos ambientais negativos oriundos da ocupação humana desordenada que, aliada à carência de planejamento urbano e ambiental, gerou problemas socioeconômicos.

Em APPs urbanas de alguns municípios, como em São João da Boa Vista-SP as ações de controle e mitigação de enchentes, previstas no Código Florestal Brasileiro, não se aplicam com efetividade na prática (GUIMARÃES; BRAGA, 2017). O mesmo problema é visualizado em Cachoeiro de Itapemirim na APP do rio Itapemirim, pois a intensa fragmentação e 0 isolamento de indivíduos arbóreos nesse local diminuem drasticamente uma das funções relevantes da APP, que é a de atenuar os impactos das enchentes do rio.

Outro fator que interfere na dinâmica da vegetação das APPs é a presença de espécies exóticas invasoras, pois as mesmas se disseminam facilmente, em contraste com espécies nativas (NAUJORKS et al., 2015). Neste estudo, embora não tenha sido avaliada a presença de espécies exóticas invasoras na APP, a ocorrência das mesmas também é evidente, como é o caso das espécies Acacia mangium Willd. e Leucaena leucocephala (Lam.) de Wit, principalmente nas áreas verdes abandonadas e outras utilizadas na arborização de vias públicas, também contabilizadas como componentes da cobertura da APP em um município que ainda não possui um Plano de Arborização Urbana.

Tais fatores impactantes associados devem ser considerados para que seja comtemplada sua redução e mitigação em um planejamento ambiental abrangente $e$ capaz de suprir as necessidades urgentes de ampliação da cobertura vegetal nas APPs da cidade. Portanto, é fundamental executar um planejamento de medidas de preservação dos resquícios de vegetação florestal e de recuperação paulatina de APPs.

Finalmente, com relação às áreas verdes do município, será necessário cobrar da administração pública a inclusão de uma previsão do aumento de áreas permeáveis às águas pluviais no Plano Diretor Municipal (PDM), o qual vem sendo atualizado no ano de 2019. Também é preciso priorizar o plantio de espécies nativas em detrimento às exóticas na arborização e, principalmente, a realização efetiva de trabalhos de educação ambiental com a população visando minimizar os impactos ambientais negativos provocados pela ação antrópica nesse trecho do rio Itapemirim que foi estudado. 


\section{CONCLUSÃO}

No ano de 2012, o percentual de vegetação florestal remanescente existente na Área de Preservação Permanente (APP), da faixa urbanizada do entorno do Rio Itapemirim, foi considerado baixo quando comparado ao constatado em outros municípios. Esse padrão é resultante da intensa urbanização de Cachoeiro de Itapemirim, que ocorreu e ainda ocorre nas margens do seu rio principal. O percentual de cobertura florestal foi maior que $40 \%$ em apenas um bairro da cidade, ao passo que os bairros localizados na região central do rio tiveram percentuais inferiores a $15 \%$. Tais percentuais evidenciam problemas quanto à manutenção dessa vegetação protetora, a qual se encontra altamente fragmentada e, que em sua maioria, ocorre sob a forma de arborização de vias públicas e quintais de residências presentes na APP investigada.

\section{REFERÊNCIAS}

ALMEIDA, C. A. S.; BURLAMAQUI, C. C. B.; ARAÚJO, F. S. de.; LUCENA JUNIOR, J. J. G. de.; ALMEIDA, J. R. de. Avaliação de impacto ambiental em uma mata ciliar na cidade de Manaus. Revista Internacional de Ciências, v. 1, n. 11, p. 1-16, 2011. Disponível em: <https://doi.org/10.12957/ric.2011.3625>. doi: 10.12957/ric.2011.362 5

ALVES, M. H.; CASTRO JUNIOR, R. M. de.; SARAIVA, J. S. T. Sistema de informações hidrológicas da Bacia do rio Itapemirim. In: IX Congresso da Associação Brasileira de Estudos do Quaternário/Il Congresso do Quaternário de Países de Línguas Ibéricas/ll Congresso sobre Planejamento e Gestão da Zona Costeira dos Países de Expressão Portuguesa, 2003, Recife. Anais... Recife: Associação Brasileira de Estudos do Quaternário, 2003.

AMARAL, D. S. S.; NASCIMENTO, A. C. S.; SANTOS, N. M. N.; SANTOS, H. F. dos.; SILVA, G. S. da. Conflitos de uso e ocupação do solo em áreas de preservação permanente no pré-assentamento Baixa Verde, Eunápolis (BA), em 2015. Revista Eletrônica Multidisciplinar Pindorama, Eunápolis, v. 8, n. 8, p. 1627, 2018. Disponível em: <https://publicacoes.ifba.edu.br/index.php/Pindorama/articl e/view/507>.

BAPTISTA, A. P. Mata Atlântica: uma abordagem geográfica. Revista Nucleus, v. 6, n. 1, p. 27-53, abr. 2009. Disponível em: < doi:http://dx.doi.org/10.3738/1982.2278. 152>. doi: $10.3738 / 1982.2278 .152$

BARROS, A. C. de; SILVA, T. J. da.; MOURA, D. de.; GARCIA, Y. M. Conflitos em áreas de preservação permanente na microbacia do Córrego da Água Amarela, Itaberá/SP. Revista Meio Ambiente e Sustentabilidade, v. 9, n. 4, p. 155-168, jul./dez. 2015. Disponível em: <http://dx.doi.org/10.22292/mas.v9i4.372>. doi: 10.22292/mas.v9i4.372

BRASIL. Lei $n^{\circ} 12.651$, de 25 de maio de 2012. Dispõe sobre a proteção da vegetação nativa e dá outras providências. 2012. 
CASTRO, J. L. S.; FERNANDES, L. da S.; FERREIRA, K. E. de J.; TAVARES, M. S. A.; ANDRADE, J. B. L. de. Mata ciliar: importância e funcionamento. In: Congresso Brasileiro de Gestão Ambiental, 8., 2017, Campo Grande. Anais... Campo Grande: IBEAS, 2017.

DAMASCENO, C. M.; SOUSA JÚNIOR, W. B. de.; PEREIRA, H. dos S.; SILVA, N. $M$. da. Fragmentos florestais como áreas protegidas em uma microbacia urbana na Amazônia. In: Encontro Latino-Americano sobre Áreas Protegidas e Inclusão Social, 1., 2013, Belo Horizonte. Anais... Belo Horizonte: Sapis, 2013.

FERREIRA, S. de S.; MENEGUELLI, A. Z. Diagnóstico ambiental de um fragmento de mata ciliar do Rio Urupá no município de Urupá - RO. Revista Saberes da UNIJIPA, Ji-Paraná, v. 5, n. 1, p. 13-27, jan./jun. 2017. Disponível em: <https://unijipa.edu.br/wp-content/uploads/Revista\%20Saberes/ed5/3.pdf>.

FIORESE, C. H. U. Comportamento temporal do uso de solo das áreas de preservação permanente do Rio Castelo - trecho urbano do município de Conceição do Castelo, ES. In: V Congresso Brasileiro de Reflorestamento Ambiental, 2018. Anais do V Congresso Brasileiro de Reflorestamento Ambiental, Vitória: CEDAGRO, 2018.

GEOBASES. lema - mapeamento ES - 2012-2015. Disponível em: <https://geobases.es.gov.br/links-para-mapes1215>. Acesso em: 4 fev. 2019.

GUIMARÃES, B. B.; BRAGA, R. Áreas de preservação permanente urbanas e as inundações em São João da Boa Vista/SP: observações sobre a aplicação do Cídigo Florestal Brasileiro no Córrego São João. In: XVII Simpósio Brasileiro de Geografia Física Aplicada e I Congresso Nacional de Geografia Física, 2017, Campinas. Anais... Campinas: Instituto de Geociências da UNICAMP, 2017.

IBGE. Sinopse do censo demográfico 2010 - Espírito Santo. Disponível em: $<$ https://censo2010.ibge.gov.br/sinopse/index.php?dados=29\&uf=32>.

IJSN. Shapefiles. Disponível em: <http://www.ijsn.es.gov.br/mapas/>. Acesso em: 2 fev. 2019.

KUDO, S. A.; PEREIRA, H. dos S.; SILVA, S. C. P. da. A proteção jurídica dos fragmentos florestais urbanos: um estudo da paisagem e da legislação ambiental e urbanística da cidade de Manaus. Revista Desenvolvimento e Meio Ambiente, v. 38, p. 521-540, ago. 2016. Disponível em: < http://dx.doi.org/10.5380/dma.v38i0.42687>. doi: 10.5380/dma.v38i0.42687

LIMA, L. B.; CASTRO, A. L.; DUARTE, M. L.; VALENTE, K. S. Uso de veículo aéreo não tripulado na avaliação de áreas de proteção permanente no município de Humaitá/AM. Revista Geonorte, v. 9, n. 32, p. 160-170, 2018. Disponível em: < http://dx.doi.org/10.21170/geonorte.2018.V.9.N.32.160.170>.

doi: 10.21170/geonorte.2018.V.9.N.32.160.170 
LIMA, S. C. de.; LIMA, F. C. de.; BASÍLIO, R. F.; MORAES NETO, J. M. de. Geoprocessamento na análise espaço-temporal da cobertura vegetal do município de Seridó - PB. Revista Científica da Faculdade de Educação e Meio Ambiente, Ariquemes, v. 9, n. 1, p. 266-275, jan./jun. 2018. Disponível em: < http://dx.doi.org/10.31072/rcf.v9i1.540>. doi: 10.31072/rcf.v9i1.540

LOUGON, M. S.; LOUZADA, F. L. R.; ROCHA, S. A.; GARCIA, G. O.; DOS SANTOS, A. R. Diagnóstico ambiental da sub-bacia hidrográfica do córrego amarelo, abordando o uso e ocupação do solo e a qualidade da água. Engenharia Ambiental, v. 6, n. 3, p. 350-367, set./dez. 2009. Disponível em: $<$ http://ferramentas.unipinhal.edu.br/engenhariaambiental/viewarticle.php?id=331>.

MOREIRA, E. B. F.; SOUZA, J. C. de. Avaliação geoambiental da área de preservação permanente do Córrego Mina d'água, Campinaçu, Goiás, Brasil. Revista de Geografia da UEG, Porangatu, v. 7, n. 1, p. 119-130, jan./jun. 2018. Disponível em: <http://www.revista.ueg.br/index.php/elisee/article/view/8089>.

NAUJORKS, E.; LAINDORF, B. L.; PUTZKE, J. Levantamento fitossociológico de vegetação ciliar do arroio Andreas na localidade de Vera Cruz, RS, Brasil. Caderno de Pesquisa, Santa Cruz do Sul, v. 27, n. 2, p. 6-19, 2015. Disponível em: < http://dx.doi.org/10.17058/cp.v27i2.6778>. doi: 10.17058/cp.v27i2.6778

OLIVEIRA, T. G. de.; FRANCISCO, C. N. Mapeamento das áreas de preservação permanente e as mudanças no código florestal. Caderno de Geografia, v. 28, n. 53, p. 574-587, 2018. Disponível em: < http://dx.doi.org/10.5752/p.23182962.2018v28n53p574>. doi: 10.5752/p.2318-2962.2018v28n53p574

ORIGE, M.; OLIVEIRA, T. de S.; JULIÃO, R. P. Integração de informações geoespaciais para analisar a ocupação do solo na área de preservação permanente da bacia hidrográfica do Rio Criciúma/SC/Brasil. Revista Geociências, São Paulo, v. 34, n. 1, p. 145-152, 2015. Disponível em: <https://www.revistageociencias.com.br /geociencias-arquivos/34/volume34_1_files/34-1-artigo-12.pdf>.

PEREIRA, B. W. F.; MACIEL, M. N. M.; OLIVEIRA, F. A.; ALVES, M. A. M. S.; RIBEIRO, A. M.; FERREIRA, B. M.; RIBEIRO, E. G. P. Uso da terra e degradação na qualidade da água na bacia hidrográfica do rio Peixe-Boi, PA, Brasil. Ambiente \& Agua, v. 11, n. 2, p. 472-485, abr./jun. 2016. Disponível em: <http://dx.doi.org/10.4136/ambi-agua.1802 >. doi: 10.4136/ambi-agua.1802

PÉRICO, E.; CEMIN, G. Caracterização da paisagem do município de Arvorezinha, $R S$, com ênfase na dinâmica dos fragmentos florestais, por meio de sistemas de informações geográficas (SIGs). Scientia Florestalis, n. 70, p. 09-21, abr. 2006. Disponível em: <https://www.ipef.br/publicacoes/scientia/nr70/cap01.pdf>.

PIROVANI, D. B.; SILVA, A. G. da.; OLIVEIRA, O. M. de.; CALIMAN, J. P. Áreas verdes urbanas de Cachoeiro de Itapemirim. Revista Enciclopédia Biosfera, Goiânia, v. 8, n. 15, p. 171-179, 2012. Disponível em: <http://www.conhecer.org.br/e nciclop/2012b/ciencias\%20agrarias/areas.pdf>. 
ROSA, M. D. A relevância ambiental das áreas de preservação permanente e sua fundamentação jurídica. Revista Internacional de Direito Ambiental e Políticas Públicas, Macapá, n. 3, p. 83-95, 2011. Disponível em: <https://periodicos.unifap.br/i ndex.php/planeta/article/view/423/0>.

SANTOS, L. A. C. Utilização dos dados do Cadastro Ambiental Rural na análise de conflitos de uso do solo em Áreas de Preservação Permanente. Tecnia, v. 3, n. 1, p. 174-196, 2018. Disponível em: < http://revistas.ifg.edu.br/tecnia/article/view/174>.

SILVA, A. M. R. C.; LOES, M. M. A aplicabilidade das normas ambientais para assentamentos rurais e preservação ambiental. Diálogos Acadêmicos, v. 10, n. 1, p. 52-65, jan./jul. 2016. Disponível em: <http://uniesp.edu.br/sites/_biblioteca/revistas /20170627113432.pdf>.

SILVA NETO, V. L.; FERREIRA JUNIOR, D. F. F.; SOUZA, P. A. de.; VIOLA, M. R. Diagnóstico ambiental da área de preservação permanente no alto curso do Córrego Dois Irmãos em Gurupi-TO. Revista Enciclopédia Biosfera, Goiânia, v. 13, n. 23, p. 470-486, 2016. Disponível em: < http://dx.doi.org/10.18677/Enciclopedia_Biosfera_2 016_042>. doi: 10.18677/Enciclopedia_Biosfera_2016_042

VESTENA, L. R.; THOMAZ, E. L. Avaliação de conflitos entre áreas de preservação permanente associadas aos cursos fluviais e uso da terra na bacia do rio das Pedras, Guarapuava-PR. Revista Ambiência, Guarapuava, v. 2, n. 1, p. 73-85, jan./jun. 2006. Disponível em: <http://www.terrabrasilis.org.br/ecotecadigital/pdf/avali acao-de-conflitos-entre-areas-de-preservacao-permanente-associadas-aos-cursos-fl uviais-e-uso-da-terra-na-bacia-do-rio-das-pedras-guarapuava-pr.pdf>. 